$\xi=$ 잘

\title{
Diode laser for excisional biopsy of pyogenic granuloma : a case series
}

\author{
Gaurav Mahajan ${ }^{1 *}$, Aditi Gautam ${ }^{2}$ \\ ${ }^{I}$ M.D.S. Student Deptt. of Periodontology. Guru Nanak Dev Dental College \& Research Institute, Sunam, Punjab India \\ ${ }^{2}$ B.D.S. Student. Guru Nanak Dev Dental College \& Research Institute, Sunam, Punjab India \\ *Corresponding author E-mail: Gauravmhjn03@gmail.com
}

\begin{abstract}
Pyogenic granuloma is one of the inflammatory hyperplasias seen in the oral cavity. This term is a misnomer because the lesion is unrelated to infection and in reality, arises in response to various stimuli such as low- grade local irritation, traumatic injury or hormonal factors. The clinical diagnosis of such as lesion can be quite challenging because of its close resemblance to certain malignancies like peripheral giant cell granuloma, kaposi's sarcoma, non hodgkin's lymphoma, etc. for excisional biopsy, options available are conventional surgical excision, electrocautery or lasers. In this report, we seek to highlight the therapeutic advantages achieved with a soft-tissue diode laser in the treatment of pyogenic granuloma.
\end{abstract}

Keywords: Pyogenic Granuloma; Diode Laser; Biopsy; Soft Tissue; H\&E Staining

\section{Introduction}

Pyogenic granuloma (PG) is a kind of inflammatory hyperplasia. The term "inflammatory hyperplasia" is used to describe a large range of nodular growths of the oral mucosa that histologically represent inflamed fibrous and granulation tissues (Eversole LR 2002 , p. 113). PG is a common tumor- like growth of the oral cavity or skin that is considered to be non- neoplastic in nature. Hullihen's description in 1844 was most likely the first PG reported in English literature, but the term PG or granuloma pyogenicum was introduced by Hartzell in 1904 (Kamal R et al. 2012) Laser systems in dental surgeries are improving at a full speed today. The diode laser is a soft-tissue laser that can be implemented for ablation of lesions, different types of biopsies, gingivo plasties, plasties, gingivectomies, soft-tissue tuberosity reductions, and certain crown lengthening procedures. More recent reports have also mentioned the diode as a possible instrument for soft tissue surgery in the oral cavity (Strauss RA 2000, Bornstein MM et al. 2003). Diode lasers show minimal postoperative swelling and scarring, improved wound healing, and decreased postoperative pain. This study reports use of diode laser with wavelength of $940 \mathrm{~nm}$ for excisional biopsy of PG.

\section{Case series}

Case- I:

A 45 years-old female patient was referred with a complaint of enlarged mass present in the left segment of the maxillary alveolar ridge with its base in vestibular region. The non- ulcerated mass was small and was approximately $14 \mathrm{~mm}$ in length and $6 \mathrm{~mm}$ in width [figure- 1(a)]. The colour and surface texture of the mass was same as normal tissue. Patient gave history of using complete denture for a last 1 year made by local quack, which was broken from different places. Based on the clinical examination and pa- tient's history a diagnosis of 'epulis fissuratum' was made. The mass was excised using diode laser $(940 \mathrm{~nm}, 4 \mathrm{~W}$, continuous mode). Excised mass was stored in formalin for histopathologic investigation [figure- 1 ( $b$ to d)]. The $\mathrm{H} \& \mathrm{E}$ stained section of the submitted tissue shows the lesional area composed of the fibrocellular tissue with loose myxoid fibrous component. The connective tissue was densely collagenous in certain areas whereas in others it showed evidence of myxomatous degeneration. The connective tissue was infiltrated with dense inflammatory infiltrate mainly composed of plasma cells and lymphocytes. Few foamy macrophages are also seen along with varying area of vascularity. The overall features were suggestive of Inflammatory Fibrous Hyperplasia [figure- 1(f)]. Follow- up examination was planned after 12 days. Since satisfactory healing was achieved after 12 days [figure- 1(e)], clinical procedures for new complete denture were initiated at the same sitting.

Case- II:

A 27 year old female patient reported 3 months postpartum with the complaint of a gingival overgrowth on the palatal and buccal aspect of the upper left premolar region. Intraoral examination revealed a gingival overgrowth measuring approximately $3 \times 3 \times 4$ $\mathrm{cm}$ presenting palatally and $1.5 \times 0.5 \mathrm{~cm}$ extending occlusally from interdental area between premolars. The palatal gingival growth was a discrete, pyramid shaped; pedunculated mass and buccal mass was triangular in shape with base extending to mucogingival junction. The lesion was magenta coloured, semi-firm in consistency and non-tender on palpation. The growth was painless but creating a problem during speech and mastication due to bleeding on slight irritation [figure- 2(a,b)]. Radiographic examination (intraoral periapical radiograph and orthopantomogram) did not reveal any bony involvement. A Gallium Aluminum Arsenide (GaAlAs) diode laser device (EPIC ${ }^{\mathrm{TM}}$ ) with the wavelength of 940 $\mathrm{nm}$ used for excision of the lesion, an output power of 2 Watt in the pulsed mode with a single use $300 \mu \mathrm{m}, 4 \mathrm{~mm}$ long fibre tip [figure- 2(c to e)]. The biopsy report showed ulcerated stratified squamous epithelium with an underlying fibrovascular stroma, 
including large number of budding capillaries, plump fibroblasts and a dense chronic inflammatory cell infiltrate. Follow-up was done after 15 days, which revealed completely healed gingival and palatal areas with no evidence of recurrence [figure- 2(f)].

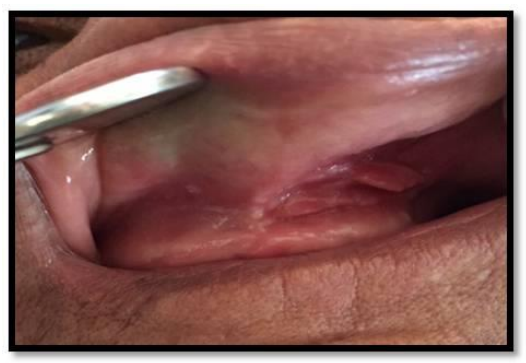

(a)

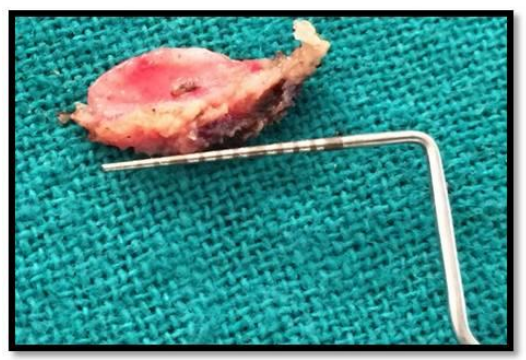

(d)

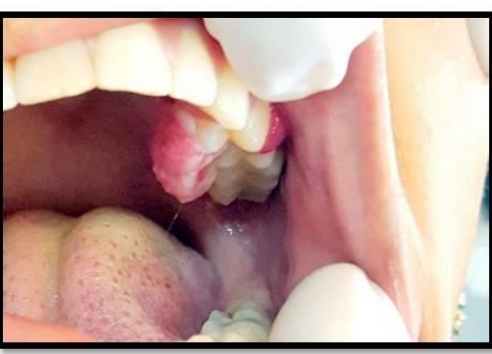

(a)

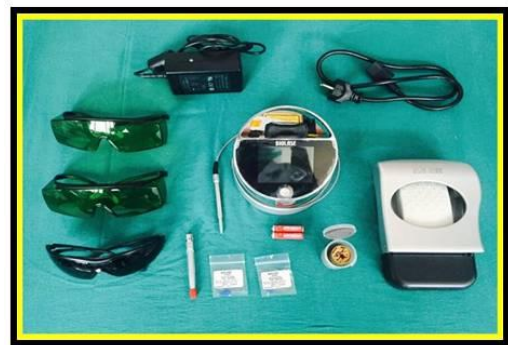

(d)

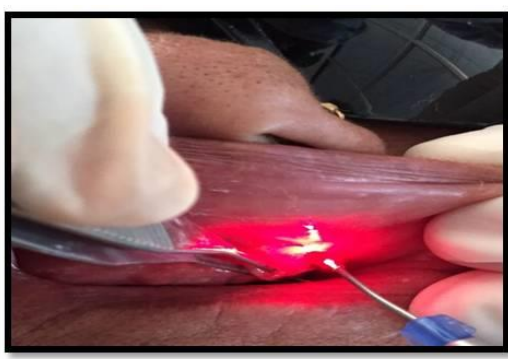

(b)

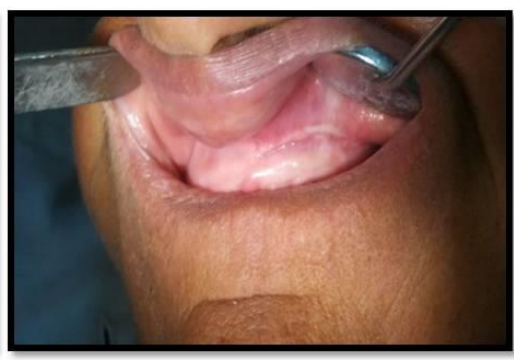

(e)

Fig. 1: (A to F)

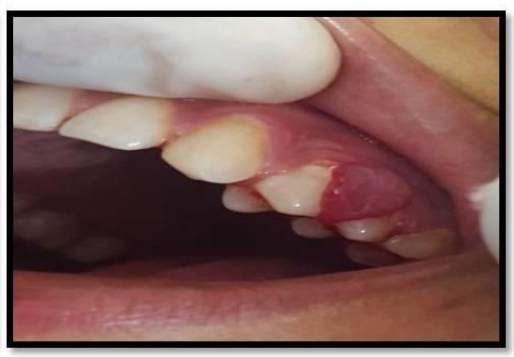

(b)

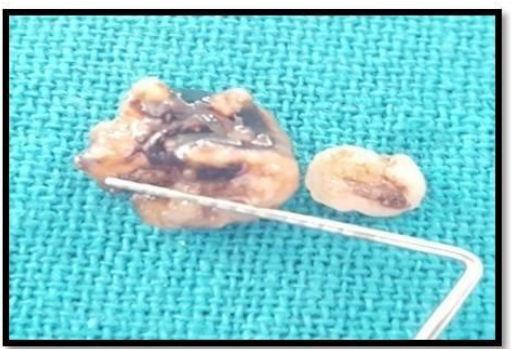

(e)

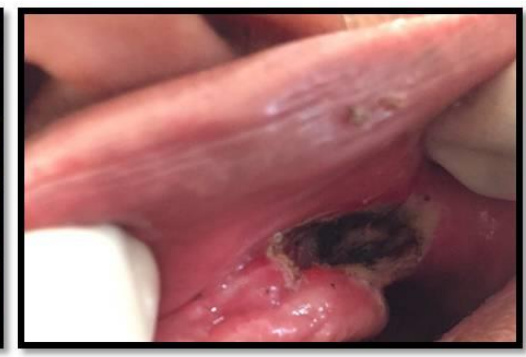

(c)

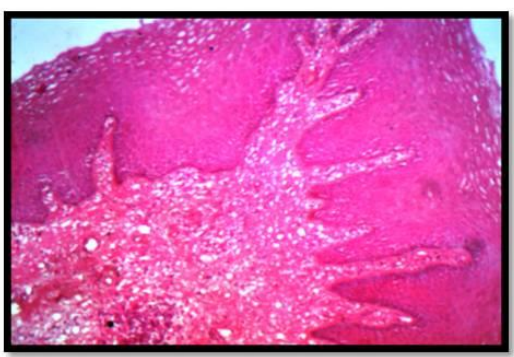

(f)

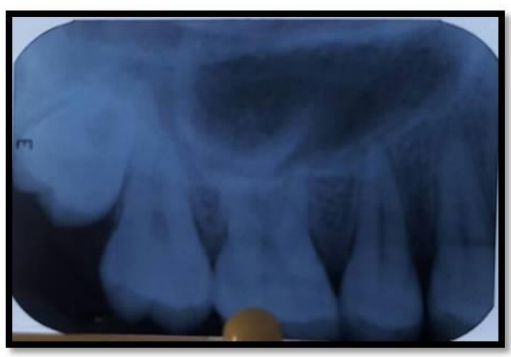

(c)

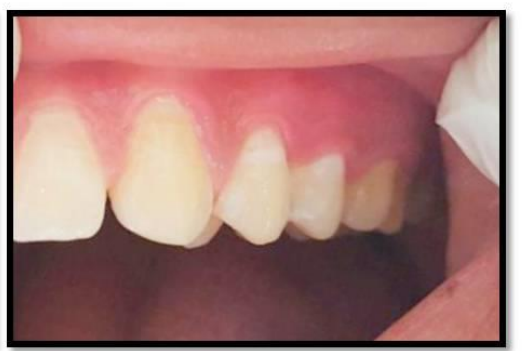

(f)

Fig. 2: (A to F)

\section{Case- III:}

A 31-year-old female patient reported with chief complaints of a nodular mass in lower right anterior segment with its base in mucogingival region since 3 months. Nodular mass increased in size from pea sized to a nodule [figure- 3(a)]. After doing phase I therapy and verifying the normal blood report, it was excised with the diode laser $(940 \mathrm{~nm}, 3 \mathrm{~W}$, continuous mode). The charred layer produced by lasering acted as a protective barrier and was not removed after this procedure [figure- 3(b,c)]. The excised mass was sent for biopsy. The $\mathrm{H} \& \mathrm{E}$ stained section of submitted tissue shows hyperplastic epithelium. The epithelium also shows focal areas of clear cells with foamy cytoplasm. The connective tissue stroma is composed of mature collagen fibres in interlacing pat- tern with calcified spicules and sparse inflammatory cell infiltration mainly composed of plasma cell and, lymphocytes. The overall features were suggestive of Focal Fibrous Hyperplasia with Calcification [figure- 3(e)]. Follow-up was done after 15 days [figure- 3(d)] which revealed completely healed gingiva and mucosa with no evidence of recurrence even after 4 months [figure1(f)]. 


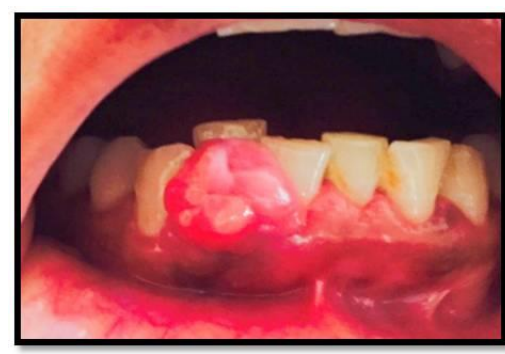

(a)

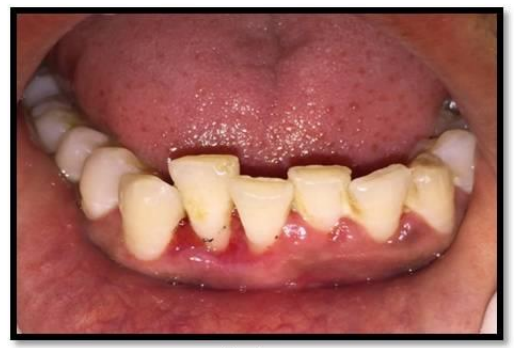

(d)

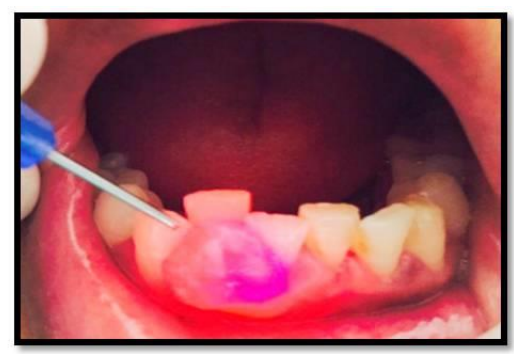

(b)

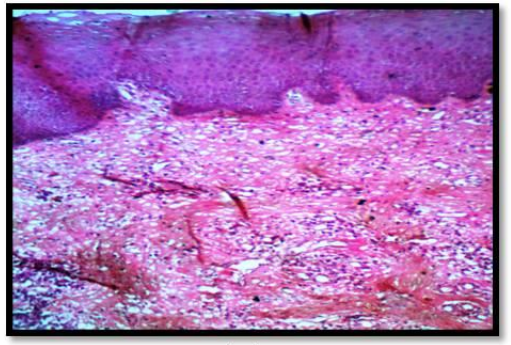

(e)

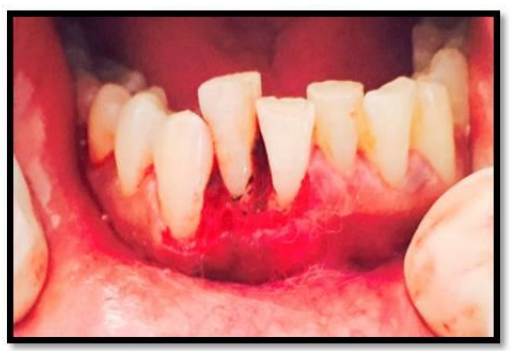

(c)

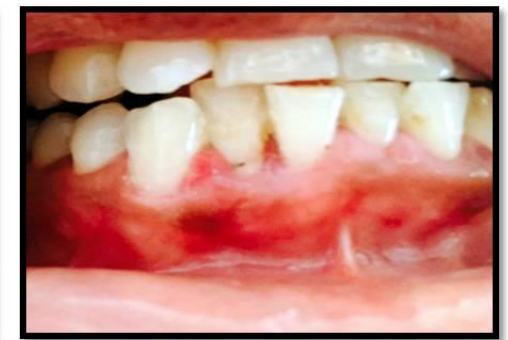

(f)

Fig. 3: (A to F).

\section{Discussion}

The usual mechanisms of diode laser that lead to ablation or decomposition of biological materials are photochemical, thermal, or plasma mediated. The rapid rise in intercellular temperature and pressure leads to cellular rupture as well as release of vapor and cellular debris, termed as the laser plume (Lagdive $S$ et al. 2009). The diode laser application, is more acceptable to the patient since the procedure takes less time and is more comfortable as there is absence of post-operative pain and hemorrhage (Asnaashari $\mathrm{M}$ et al. 2015, Sotoode SM et al. 2015). One of the studies found that the subjects experienced a higher extent of discomfort/pain in the side treated by the surgical removal as compared with the diode laser-treated side during the first post-therapy week (Ribeiro FV et al. 2014). Also, from the operator's point of view, the laser technique is easier and faster to perform than the surgical scraping technique (Kende $\mathrm{P}$ et al. 2011, Shankar S et al. 2014). All procedures were performed without pain, and no sutures were necessary.

\section{Conclusion}

Diode lasers can be used for excisional biopsy procedure and especially small prominent lesions because of easy application, better coagulation, no need for suturing, less swelling and pain, faster action, better de-epithelialization and better repair

\section{References}

[1] Eversole LR (2002) Clinical outline of oral pathology: diagnosis and treatment. $3^{\text {rd }}$ ed, BC Decker, Hamilton, 113-114.

[2] Kamal R, Dahiya P, Puri A (2012) Oral pyogenic granuloma: Various concepts of etiopathogenesis. J Oral Maxillofac Pathol. 16(1): 79-82. https://doi.org/10.4103/0973-029X.92978.

[3] Strauss RA (2000) Lasers in oral and maxillofacial surgery. Dent Clin North Am. 44(4):851-73.

[4] Bornstein MM, Suter VGA, Stauffer E, Buser D (2003) The CO2 laser in stomatology: Part 1. Schweiz Monatsschr Zahnmed.113: $559-70$.

[5] Lagdive S, Doshi Y, Marawar PP (2009) Management of gingival hyperpigmentation using surgical blade and diode laser therapy: A comparative study. J Oral Laser Applications.9:41-7.

[6] Asnaashari M, Mehdipour M, MoradiAbbasabadi F, Azari-Marhabi S (2015) Expedited Removal of Pyogenic Granuloma by Diode La- ser in a Pediatric Patient. Journal of Lasers in Medical Sciences 6(1):40-44.

[7] Sotoode SM, Azimi S, Taheri SA, Asnaashari M, Khalighi H, Rahmani S, Jafari S, Elmi Rankohi Z (2015) Diode Laser in Minor Oral Surgery: A Case Series of Laser Removal of Different Benign Exophytic Lesions. Journal of Lasers in Medical Sciences. 6(3):133-138. https://doi.org/10.15171/jlms.2015.08.

[8] Ribeiro FV, Cavaller CP, Casarin RC, Casati MZ, Cirano FR, Dutra - Correa M, Pimentel SP (2014) Esthetic treatment of gingival hyperpigmentation with Nd:YAG laser or scalpel technique: a 6 month RCT of patient and professional assessment. Lasers Med Sci. 29(2):537-44. https://doi.org/10.1007/s10103-012-1254-5.

[9] Kende P, Gaikwad R, Yuwanati M, Jain B (2011) Application of Diode Laser in Oral Biopsy: Removal of White Patch over Tongue - A Case Report. JIDA; 5(9).

[10] Shankar S, Gokhale ST, Agarwal A, Manjunath RGS (2014) LASER Assisted Excision of Pyogenic Granuloma Associated with Localized Alveolar Bone Loss: A Case Report. IJSS; 2(2). 